\title{
Telecommunication in Diagnostic Surgical Pathology: History-Present Stage-Expectations
}

\section{Klaus Kayser ${ }^{1 *}$, Stephan Borkenfeld ${ }^{2}$ and Gian Kayser ${ }^{3}$}

${ }^{1}$ Institute of Pathology, University of Medicine, Berlin, Germany 2International Academy of Telepathology, Heidelberg, Germany

${ }^{3}$ Institute of Pathology, University of Freiburg, Freiburg, Germany

\section{Background}

Communication is one essential prerequisite of man, and forms the basic structure of life. The recently developed technical tools have great impact on all issues of human behaviour, allowing nearly unlimited assistance in problem related actions as well as causing irritations and severe damages in distinguishing virtual worlds from physical reality [1]. What does surgical pathology loose or benefit from these changes?

\section{Historical Consideration}

Medical telecommunication is limited to the transmission and receipt of acoustic and visual signals. Starting in the early 1980s the electronic transmission of both analogue acoustic and visual signals was successfully implemented in bridging several hundred kilometres [2]. Public telephony which is the commonly used acoustic communication was first, followed by the transfer of images, i.e., television and FAX about 50 years later [2]. Both techniques are digitized in our days, and called multimedia if applied contemporary. In surgical pathology they serve for two different principle aims: evaluation of the first diagnosis (frozen section services), and assurance of the obtained diagnostic statement (expert consultation). The procedure is called telepathology [3]. The first reports of successful telepathology range back in the early 1980s: Eide and Norstrom reported successful application of telepathology in routine frozen section services, Weinstein et al. [4] as well as Kayser et al. [5] in routine diagnosis assurance. Having demonstrated the general use and practice of telepathology [6], the technology was refined by investigations in image quality, stability of line connections, velocity of image judgement, and details of workflow adjustment [7]. Based upon these investigations it is generally agreed that TV displayed diagnosisrelevant images are equivalent to "native" microscopic images, that TV based diagnoses possess the same potential diagnosis failure rate, and that 2-dimensional TV images are sufficient for histological diagnosis, in contrast to cytological diagnoses which might require an additional $3 \mathrm{D}$ axis [8].

\section{Present Stage}

The present stage of telepathology is characterized by general communication standards which are in use for internet based communication. In addition, matured commercially available whole slide scanners contribute which can digitize a complete histological slide in less than one minute [9]. Analogue telepathology has nearly completely been replaced by digital tools, which coordinate the patient's identity and the submitted tissue (barcode), document gross findings of resection tissues (macroscopic images), communicate with the Laboratory Information System (LIS) and the Hospital Information System (HIS), define the record and image standards (Digital Imaging and Communication in Medicine, DICOM, Picture Archiving and Communication System PACS), and use digital tools to steer and assist the pathologist's diagnostic work. Herein, two different applications are in focus: a) to assist in routine diagnosis, and b) to measure and quantify image information [3]. Assistance in routine diagnosis tries to adjust the displayed image size to the physical human view field, colour sensitivity, to implement good performance, etc. Image measurements address to so-called predictive diagnosis, and grade the visualized expression of antibody binding sites, gene modifications and expressions, or membrane bound communication targets (for example Epidermal Growth Factor Receptor (EGFR), hormone receptors, etc.). An automated selection of diagnosis relevant image areas (Region of Interest (ROI) as well as automated assessment of the most appropriate image magnification combines both aims: to prepare tools for faster and more precise diagnosis [10].

However, when taking a look to acceptance and implementation into routine diagnostic work, the result is quite disappointing: Only a few Institutes of Pathology are using this technology in routine diagnosis despite nearly all of them possess a virtual slide scanner, and despite to broad experimental use for pharmaceutical applications. In addition, digital telecommunication is often applied for teaching, in so-called clinical-pathology conferences, and partly for expert consultation [11].

Why does routine surgical pathology avoid digital image technology? The answer to this question directs to the potential future development and perspectives.

\section{Perspectives}

At present, the main handicap of telecommunication in surgical pathology is related to its "non integrative" or "non communicative" features: For most potential applications digital pathology and especially virtual microscopy have been designed in "stand-alone" performance [12]. Standards to communicate with LIS and HIS missing as well as "complete solutions" offered by industry. Authoritative virtual slide image standards are missing too, and each company works with its closed individual image structures. In addition, most of the vendors do not distinguish between different aims of application, for example between an "interactive", i.e. human or surgical pathologist oriented diagnostic performance and automated diagnosis programs designed for pre-screening and pre-selection of submitted cases. These drawbacks are well known and appropriate research and industrial mercantile considerations will probably overcome these constraints in the next few years. Especially ongoing industrial concentration efforts and the high amount of invested money point to this development. The conservative behaviour of surgical pathologists which has been frequently argued against digital microscopy and related fields will probably no longer play a significant role in the near future: most

*Corresponding author: Klaus Kayser, Institute of Pathology, Charite Mitte University of Medicine, Berlin, Germany, E-mail: Klaus.kayser@charite.de

Received November 12, 2012; Accepted November 14, 2012; Published November 16, 2012

Citation: Kayser K, Borkenfeld S, Kayser G (2012) Telecommunication in Diagnostic Surgical Pathology: History-Present Stage-Expectations. J Telecommun Syst Manage 1:e106. doi:10.4172/2167-0919.1000e106

Copyright: ( 2012 Kayser K, et al. This is an open-access article distributed under the terms of the Creative Commons Attribution License, which permits unrestricted use, distribution, and reproduction in any medium, provided the original author and source are credited. 
Citation: Kayser K, Borkenfeld S, Kayser G (2012) Telecommunication in Diagnostic Surgical Pathology: History-Present Stage-Expectations. J Telecommun Syst Manage 1:e106. doi:10.4172/2167-0919.1000e106

Page 2 of 2

young pathologists are grown up with computers, and are familiar with mobile communication and open access forums.

\section{References}

1. Kayser K, Borkenfeld S, Goldmann T, Kayser G (2012) To be at the right place at the right time. Diagn Pathol 6: 2-9

2. Kayser K, Borkenfeld S, Djenouni A, Kayser G (2011) History and structures of telecommunication in pathology, focusing on open access platforms. Diagn Pathol 6: 110

3. Kayser K, Molnar B,Weinstein RS (2006) Virtual Microscopy - Fundamentals - Applications - Perspectives of Electronic Tissue - Based Diagnosis. VSV Interdisciplinary Medical Publishing.

4. Weinstein RS, Graham AR, Richter LC, Barker GP, Krupinski EA, et al. (2009) Overview of telepathology, virtual microscopy, and whole slide imaging: prospects for the future. Hum Pathol 40: 1057-1069

5. Kayser K, Fritz P, Drlicek M, Rahn W (1995) Expert consultation by use of telepathology--the Heidelberg experiences. Anal Cell Pathol 9: 53-60
6. Nordrum I, Engum B, Rinde E, Finseth A, Ericsson H, et al. (1991) Remote frozen section service: a telepathology project in northern Norway. Hum Pathol 22: $514-518$

7. Yagi Y, Rojo MG, Kayser K, Kayser G, Laurinavicius A, et al. (2012) The First Congress of the International Academy of Digital Pathology: digital pathology comes of age. Anal Cell Pathol (Amst) 35: 1-2

8. Zwonitzer R, Hofmann H, Roessner A, Kalinski T (2012) Virtual 3D microscopy in pathology education. Hum Pathol 41: 457-458

9. Weinstein RS (2008) The S-curve framework: predicting the future of anatomic pathology. Arch Pathol Lab Med 132: 739-742

10. Gortler J, Berghoff M, Kayser G, Kayser K (2006) Grid technology in tissuebased diagnosis: fundamentals and potential developments. Diagn Pathol 1: 23

11. van den Tweel JG, Bosman FT (2010) The use of virtual slides in the EUROPALS examination. Diagn Pathol 6: S23

12. Kayser K (2011) Introduction of virtual microscopy in routine surgical pathology-a hypothesis and personal view from Europe. Diagn Pathol 7: 48 